\title{
HIGH LEVEL SWIMMING PERFORMANCE AND ITS RELATION TO NON-SPECIFIC PARAMETERS: A CROSS-SECTIONAL STUDY ON MAXIMUM HANDGRIP ISOMETRIC STRENGTH ${ }^{1,2}$
}

\author{
NUNO D. GARRIDO, ANTÓNIO J. SILVA, \\ Research Centre in Sports, \\ Health and Human Development (CIDESD) \\ University of Trás-os-Montes and Alto Douro, Portugal \\ RICARDO J. FERNANDES \\ CIFI2D, Faculty of Sports \\ University of Porto, Portugal \\ TIAGO M. BARBOSA \\ Research Centre in Sports, Health \\ and Human Development (CIDESD) \\ Department of Sport Sciences \\ Polytechnic Institute of Bragança, Portugal
}

\author{
ALDO M. COSTA, DANIEL A. MARINHO, MÁRIO C. MARQUES \\ Research Centre in Sports, Health and Human Development (CIDESD) \\ Department of Sport Sciences, University of Beira Interior, Portugal
}

\begin{abstract}
Summary.-The relationship between handgrip isometric strength and swimming performance was assessed in the four competitive swimming strokes in swimmers of different age groups and of both sexes. 78 national-level Portuguese swimmers (39 males, 39 females) were selected for this study. Grip strength, previously used as a marker of overall strength to predict future swimming performance, was measured using a hand dynamometer. The best competitive time at 100 and $200 \mathrm{~m}$ in all four swimming strokes were converted into 2010 FINA points. Non-parametric tests were used to evaluate differences between groups. Pearson product-moment correlations were computed to verify the association between variables. Handgrip maximum isometric strength was significantly correlated with swimming performance, particularly among female swimmers. Among female age group swimmers, the relationship between handgrip and 100-m freestyle was significant. Handgrip isometric strength seems to be related to swimming performance, especially to 100$\mathrm{m}$ freestyle and in female swimmers. For all other distances and strokes, technique and training probably are more influential than semi-hereditary strength markers such as grip strength.
\end{abstract}

Researchers have attempted to identify characteristics that differentiate skilled from less skilled performers and to identify the role of talent and environment in the development of expertise (Reilly, Williams, \&

\footnotetext{
${ }^{1}$ Address correspondence to Daniel A. Marinho, Sports Science Department, University of Beira Interior, Rua Marquês d'Ávila e Bolama, 6201-001 Covilhã, Portugal or e-mail (dmarinho @ubi.pt).

${ }^{2}$ The authors thank the swimmers who participated in this study and the Portuguese Swimming Federation for authorization and technical assistance. This work was supported by grants from the University of Beira Interior/Santander (UBI/FCSH/Santander/2010-2012).
} 
Richardson, 2008). Currently, talent identification represents a judgment about future performance based on the present individual skills and abilities (Silva, Costa, Oliveira, Reis, Saavedra, Perl, et al., 2007). For competitive swimming, several models have been proposed for predicting sports performance (e.g., Blanksby, 1980; Kjendlie, Ingjer, Stallman, \& Stray-Gundersen, 2004; Silva, et al., 2007), most of which included strength and muscle power-related variables (e.g., Tanaka, Costill, Thomas, Fink, \& Widrick, 1993; Tanaka \& Swensen, 1998). In fact, as the water offers significant resistance to the swimmers' forward movements, they must generate high propulsive forces to overcome hydrodynamic drag, which increases as the cubic power of velocity (Nigg, 1983). Thus, swimmers must generate maximum force and optimally direct it during maximum performance or at high intensities (Marinho, Barbosa, Reis, Kjendlie, Alves, Vilas-Boas, et al., 2010). As such, muscle strength is not a whole-body characteristic but is dependent on the ability and trainability of specific body segments to perform the desired movement (Pearson, Naughton, \& Torode, 2006).

During the last two decades, several authors have attempted to isolate from a wide range of variables those that determine mostly the success in competition in several sports (Bloom, 1985; Bompa, 1985; Bloomfield, 1995; Fernandes, Marinho, Barbosa, \& Vilas-Boas, 2006). Even before this assumption, for example, previous studies found that maximal swimming velocity is highly related to maximal force production $(r=.86$; Keskinen, Tilli, \& Komi, 1989), namely in shorter duration events (Toussaint \& Vervoorn, 1990; Klentrou \& Montpetit, 1991; Geladas, Nassis, \& Pavlicevic, 2005; Stager, \& Coyle, 2005; Morouço, Keskinen, Vilas-Boas, \& Fernandes, 2011) and in swimmers over 15 years old (Watanabe \& Takai, 2005). Unfortunately, despite the series of assessments and types of analysis, the prediction of performance based on swimmers' strength is still imprecise. Several studies in swimming performance have reported results from strength testing, but such tests may not relate to the swimming-specific context, especially when load and movement velocity are held constant (Sharp, Troup, \& Costill, 1982; Olbrecht, Madsen, Mader, Liesen, \& Hollmann, 1985; Dopsaj, Matkovic, Thanopoulos, \& Okicic, 2003; Kjendlie, \& Thorsvald, 2006). A particularly clear example of this situation is the handgrip isometric strength test, recently associated with swimming performance in young (Geladas, et al., 2005) and elite master swimmers (Zampagni, Casino, Benelli, Visani, Marcacci, \& De Vito, 2008), and also included in talent identification models (Carzola, 1993; Silva, et al., 2007).

The handgrip test has been systematically used in several populations other than swimmers (Frederiksen, Hjelmborg, Mortensen, McGue, Vaupel, \& Christensen, 2006; Milliken, Faigenbaum, Loud, \& Westcott, 2008) and related with distinct sports performance, as in soccer (Cortis, Tessitore, 
Perroni, Lupo, Pesce, Ammendolia, et al., 2009), tennis (Girard \& Millet, 2009), handball (Visnapuu \& Jürimäe, 2007, 2009), basketball (Visnapuu \& Jürimäe, 2007), baseball (Hughes, Lyons, \& Mayo, 2004), and weightlifting (Fry, Ciroslan, Fry, Leroux, Schilling, \& Chiu, 2006). Additionally, this strength parameter discriminates functioning in all age groups (Mathiowetz, Kashman, Volland, Weber, Dowe, \& Rogers, 1985), being highly correlated with power in other muscular groups (Rantanen, Pertti, Kauppinen, \& Heikkinen, 1994), and associated with total body strength (Carmelli \& Reed, 2000; Foo, 2007).

A possible explanation for why grip isometric strength might be used as a potential proxy measure for talent identification is because it is considered a phenotype that reflects physical function with relatively high heritability (Frederiksen, Gaist, Christian Petersen, Hjelmborg, McGue, Vaupel, et al., 2002). The theory is that the swimmers with high hereditary body strength will be more likely to meet their performance potential as they reach adulthood. This could be particularly relevant because strength development is significantly linked to maturation status (Hansen, Bangsbo, Twisk, \& Klausen, 1999) and is largely modifiable through well-implemented training interventions (Garrido, Marinho, Reis, van den Tillaar, Costa, Silva, et al., 2010). As such, pre-training strength measures are unlikely to be predictive of the athlete's potential (Pearson, et al., 2006), unless those values are genetic markers with importance of the same order as growth and training variables.

In view of the foregoing, the present study assessed the relationship between handgrip isometric strength and swimming performance in the four competitive swimming strokes and determined whether this relationship remains constant in high-level swimmers from several age groups and of both sexes. In addition, it was hypothesized that handgrip isometric strength would increase across age groups, being significantly higher among male swimmers at short distances.

\section{METHOD}

\section{Participants}

Seventy-eight top national-level Portuguese swimmers (39 males, 39 females) were selected for this study: (i) 21 juvenile swimmers (11 boys, 10 girls; $M$ boys' age $=15.0$ yr., $S D=0.5 ; M$ girls' age $=12.5 \mathrm{yr}$., $S D=0.5$ ), (ii) 24 junior swimmers (10 boys, 14 girls; $M$ boys' age $=16.4$ yr., $S D=0.5 ; M$ girls' age $=14.6$ yr., $S D=0.5$ ), and (iii) 33 senior swimmers (18 men, 15 women; $M$ men's age $=21.3$ yr., $S D=2.3 ; M$ women's age $=18.6$ yr., $S D=2.3$ ). Thus, the sample was studied both by age and sex groups. It was not possible to adjust for biological maturity status, as no measure was available. The participants' characteristics are presented in Table 1. These swimmers 
TABLE 1

Descriptive Statistics for Participants' Characteristics by Age and Sex Groups

\begin{tabular}{|c|c|c|c|c|c|c|c|c|c|c|c|c|}
\hline \multirow[t]{3}{*}{ Characteristic } & \multicolumn{4}{|c|}{ Juvenile } & \multicolumn{4}{|c|}{ Junior } & \multicolumn{4}{|c|}{ Senior } \\
\hline & \multicolumn{2}{|c|}{$\begin{array}{l}\text { Males } \\
(n=11)\end{array}$} & \multicolumn{2}{|c|}{$\begin{array}{c}\text { Females } \\
(n=10)\end{array}$} & \multicolumn{2}{|c|}{$\begin{array}{l}\text { Males } \\
(n=10)\end{array}$} & \multicolumn{2}{|c|}{$\begin{array}{c}\text { Females } \\
(n=14)\end{array}$} & \multicolumn{2}{|c|}{$\begin{array}{l}\text { Males } \\
(n=18)\end{array}$} & \multicolumn{2}{|c|}{$\begin{array}{c}\text { Females } \\
(n=15)\end{array}$} \\
\hline & $M$ & $S D$ & $M$ & $S D$ & $M$ & $S D$ & $M$ & $S D$ & $M$ & $S D$ & $M$ & $S D$ \\
\hline Age, yr. & 14.96 & 0.50 & 12.53 & 0.49 & 16.36 & 0.50 & 14.63 & 0.48 & 21.80 & 2.33 & 18.63 & 2.29 \\
\hline Weight, kg & 64.84 & 7.48 & 54.54 & 11.40 & 68.99 & 7.18 & 58.99 & 8.18 & 76.24 & 6.13 & 57.55 & 4.77 \\
\hline Height, cm & 177.70 & 6.40 & 162.70 & 8.54 & 180.30 & 2.76 & 167.79 & 6.32 & 181.67 & 5.92 & 165.64 & 4.53 \\
\hline
\end{tabular}

were in a national program for high-level swimmers, comprising $96 \%$ of that total population.

The participants and their parents (when swimmers were under 18 years old) provided written informed consent, as per procedures approved by the local institutional review board and carried out according to the Helsinki Declaration. The age differences between sexes in the same age group are due to the Ligue Européenne de Natation rules, which imposes that girls should be two years younger when compared with boys (due to a supposed earlier biological maturation).

\section{Anthropometric Measurements}

All participants had standard anthropometric measures taken (height and body mass) according to the International Working Group on Kinanthropometry methodology (Ross \& Marfell-Jones, 1991). A stadiometer (SECA, model 225, Germany) was used to evaluate height with a range scale of $0.10 \mathrm{~cm}$. Body mass was measured to the nearest $0.1 \mathrm{~kg}$ using a digital scale (Philips, type HP 351/00).

\section{Strength Measurements}

Grip isometric strength was measured using an adjustable mechanical hand dynamometer (Lafayette Instrument, Lafayette, IN). For both the dominant and non-dominant hand and regardless of the sex, grip isometric strength is greater with a fully extended elbow (Oxford, 2000). The hand dynamometer was adjusted at the most comfortable distance as decided by the participant. After a warm-up period of about 10 minutes, each participant underwent a familiarization session after instructions about proper handgrip technique. Then, the participants were instructed to exert their maximal grip with the upper limb in extension in three trials, with brief pauses between each ( 2 minutes). The average result was used for analysis (Haidar, Kumar, Bassi, \& Deshmukh, 2004). It should be noted that all swimmers studied had already undergone previous assessments with this instrument. 


\section{Performance}

The participants were asked to report their best times recorded in 100$\mathrm{m}$ and 200-m butterfly, backstroke, breaststroke, and front crawl in competition. The mean time gap between the oldest and the most recent personal best was 4.5 mo. $(S D=1.1)$. Those times were converted into 2010 FINA points (a system that distinguishes values for each performance, based on the latest world record approved by FINA) to allow comparison of performances in different events.

\section{Data Analysis}

Means and standard deviations were calculated for each variable. The Kolmogorov-Smirnov test of normality and Levine's test of homogeneity of variance were performed to assess the normality of the distribution. All differences between sexes were calculated by a Mann-Whitney test. Furthermore, within each sex, analyses of the data across the three age groups were done by Kruskal-Wallis Test. Spearman's rho correlation coefficient was computed to investigate relationships between handgrip isometric strength and swimming performance. To account for differences in body size, handgrip isometric strength was also expressed per kilogram of body weigh. Data was analyzed using SPSS 12.0 (Chicago, IL, 2003). Significance was set at $p<.05$.

\section{Results}

Table 2 presents the descriptive statistics for the handgrip for both the dominant hand and non-dominant hand. There were no statistically significant differences in handgrip strength between dominant and non-dominant hands in the groups considered. Within each sex, the grip strength

TABLE 2

Descriptive Statistics for Participants' Handgrip Strength, by Age and Sex

\begin{tabular}{|c|c|c|c|c|c|c|c|c|}
\hline \multirow{3}{*}{$\begin{array}{l}\text { Grip } \\
\text { Strength }\end{array}$} & \multicolumn{4}{|c|}{ Juvenile } & \multicolumn{4}{|c|}{ Junior } \\
\hline & \multicolumn{2}{|c|}{$\begin{array}{l}\text { Males } \\
(n=11)\end{array}$} & \multicolumn{2}{|c|}{$\begin{array}{c}\text { Females } \\
(n=10)\end{array}$} & \multicolumn{2}{|c|}{$\begin{array}{l}\text { Males } \\
(n=10)\end{array}$} & \multicolumn{2}{|c|}{$\begin{array}{c}\text { Females } \\
(n=14)\end{array}$} \\
\hline & $M$ & $S D$ & $M$ & $S D$ & $M$ & $S D$ & $M$ & $S D$ \\
\hline Dominant hand, kg & 46.60 & 9.73 & 32.83 & 5.45 & 48.13 & 7.74 & 30.93 & 4.28 \\
\hline \multirow[t]{3}{*}{ Non-dominant hand, $\mathrm{kg}$} & 43.47 & 7.80 & 30.73 & 4.98 & 44.50 & 5.69 & 28.74 & 5.34 \\
\hline & \multicolumn{4}{|c|}{ Senior } & & & & \\
\hline & \multicolumn{2}{|c|}{$\begin{array}{c}\text { Males } \\
(n=18)\end{array}$} & \multicolumn{2}{|c|}{$\begin{array}{c}\text { Females } \\
(n=15)\end{array}$} & & & & \\
\hline Dominant hand, kg & 51.96 & 5.85 & 33.50 & 5.92 & & & & \\
\hline Non-dominant hand, $\mathrm{kg}$ & 48.19 & 7.70 & 31.07 & 6.25 & & & & \\
\hline
\end{tabular}


TABLE 3

Spearman's Rho Coefficients Between Handgrip Strength and Swimming Performance in Females by Age Group and Stroke

\begin{tabular}{|c|c|c|c|c|c|c|c|c|c|}
\hline \multirow{2}{*}{$\begin{array}{l}\text { Grip Strength } \\
\text { Measure }\end{array}$} & \multirow{2}{*}{$\begin{array}{l}\text { Age } \\
\text { Group }\end{array}$} & \multicolumn{2}{|c|}{ Butterfly } & \multicolumn{2}{|c|}{ Backstroke } & \multicolumn{2}{|c|}{ Breaststroke } & \multicolumn{2}{|c|}{ Freestyle } \\
\hline & & $100 \mathrm{~m}$ & $200 \mathrm{~m}$ & $100 \mathrm{~m}$ & $200 \mathrm{~m}$ & $100 \mathrm{~m}$ & $200 \mathrm{~m}$ & $100 \mathrm{~m}$ & $200 \mathrm{~m}$ \\
\hline \multirow[t]{3}{*}{ Dominant hand } & Juvenile & $.77 \dagger$ & .66 & .46 & .35 & .13 & .14 & $.82 \dagger$ & $.65^{*}$ \\
\hline & Junior & .47 & .28 & -.27 & -.33 & $.74 \dagger$ & $.94 \dagger$ & $.62 \dagger$ & .21 \\
\hline & Senior & -.01 & -.24 & .12 & .06 & -.04 & -.26 & $.54 \dagger$ & $.59 \dagger$ \\
\hline \multirow{3}{*}{$\begin{array}{l}\text { Dominant hand } / \mathrm{kg} \\
\text { body weight }\end{array}$} & Juvenile & .30 & -.09 & -.36 & .33 & -.17 & .12 & .27 & -.12 \\
\hline & Junior & .11 & .18 & .06 & .27 & .18 & .29 & -.31 & -.33 \\
\hline & Senior & .08 & -.35 & .19 & .15 & .01 & -.16 & $.59^{*}$ & $.61^{*}$ \\
\hline \multirow[t]{3}{*}{ Non-dominant hand } & Juvenile & .62 & $.89 \dagger$ & .45 & .25 & .08 & -.13 & .60 & .51 \\
\hline & Junior & $.54^{*}$ & .37 & -.54 & -.53 & $.77 \dagger$ & $.86 \dagger$ & .53 & .34 \\
\hline & Senior & -.06 & -.45 & .22 & .21 & -.07 & -.02 & $.53 \dagger$ & $.51 \dagger$ \\
\hline \multirow{3}{*}{$\begin{array}{l}\text { Non-dominant hand / } \\
\text { kg body weight }\end{array}$} & Juvenile & -.02 & .20 & -.32 & .31 & -.03 & -.29 & -.22 & -.53 \\
\hline & Junior & .32 & .31 & -.42 & -.24 & .44 & .55 & -.06 & -.04 \\
\hline & Senior & .14 & -.35 & .33 & .26 & .13 & .11 & $.55^{\star}$ & .46 \\
\hline
\end{tabular}

${ }^{*} p<.05 . \dagger p<.01$.

for both hands did not vary significantly between age groups. The handgrip was significantly higher among males in all age groups measured.

Table 3 shows the correlations between handgrip isometric strength and swimming performance in females. There were a few statistically significant positive correlations between the grip isometric strength in both hands and the performance in different competitions and age groups. However, the relationship between the handgrip strength in the dominant

TABLE 4

Spearman's Rho Coefficients Between Handgrip Strength and Swimming Performance in Males by Age Group and Stroke

\begin{tabular}{|c|c|c|c|c|c|c|c|c|c|}
\hline \multirow{2}{*}{$\begin{array}{l}\text { Grip Strength } \\
\text { Measure }\end{array}$} & \multirow{2}{*}{$\begin{array}{l}\text { Age } \\
\text { Group }\end{array}$} & \multicolumn{2}{|c|}{ Butterfly } & \multicolumn{2}{|c|}{ Backstroke } & \multicolumn{2}{|c|}{ Breaststroke } & \multicolumn{2}{|c|}{ Freestyle } \\
\hline & & $100 \mathrm{~m}$ & $200 \mathrm{~m}$ & $100 \mathrm{~m}$ & $200 \mathrm{~m}$ & $100 \mathrm{~m}$ & $200 \mathrm{~m}$ & $100 \mathrm{~m}$ & $200 \mathrm{~m}$ \\
\hline \multirow[t]{3}{*}{ Dominant hand } & Juvenile & .02 & -.02 & .21 & -.35 & -.36 & -.23 & $.63^{*}$ & -.01 \\
\hline & & .56 & .26 & .07 & -.41 & .22 & -.12 & .49 & -.18 \\
\hline & & -.04 & -.34 & .17 & -.20 & .19 & .23 & .31 & .26 \\
\hline \multirow{3}{*}{$\begin{array}{l}\text { Dominant hand / } \mathrm{kg} \\
\text { body weight }\end{array}$} & Juve & .10 & -.10 & .24 & -.19 & -.22 & -.12 & .39 & .07 \\
\hline & Junic & .24 & -.11 & .24 & -.05 & -.03 & -.35 & .28 & -.19 \\
\hline & & -.03 & -.3 & .0 & -.29 & .2 & .3 & .39 & .37 \\
\hline \multirow[t]{3}{*}{ Non-dominant hand } & Juvenile & -.20 & .05 & .25 & -.24 & -.33 & -.24 & $.71^{*}$ & -.17 \\
\hline & Junior & .62 & .19 & .11 & -.25 & .26 & -.04 & .55 & -.12 \\
\hline & Senior & -.17 & -.29 & .26 & -.06 & .12 & .18 & .04 & .07 \\
\hline \multirow{3}{*}{$\begin{array}{l}\text { Non-dominant hand / } \\
\text { kg body weight }\end{array}$} & Juven & -.07 & -.26 & .26 & .12 & -.07 & -.12 & .38 & -.02 \\
\hline & Junio & -.08 & -.31 & .07 & .01 & .07 & -.33 & .13 & -.08 \\
\hline & Senior & -.18 & -.32 & .19 & -.11 & .30 & .38 & .12 & .16 \\
\hline
\end{tabular}

${ }^{{ }^{*}} p<.05 . \dagger p<.01$. 
hand and 100-m freestyle performance was the only one observed in all three age groups. No statistically significant correlations were found for handgrip isometric strength when expressed per kilogram of body weight.

Table 4 presents the correlations between handgrip isometric strength and swimming performance in males. The results show that the performance in the 100-m freestyle was the only swimming event having a statistically significant correlation with grip strength, and that only among the juvenile swimmers.

\section{Discussion}

In this study, the correlations between handgrip isometric strength and specific swimming performances were analyzed in three age groups and in both sexes. The use of parameters with high hereditary coefficients may be useful in models that attempt to predict sports performance. However, given the overall low correlations found here (particularly for the boys), it appears that whatever hereditary relationship there might be is overwhelmed by environmental conditions, including early training, diet, and learned coordination associated with muscle use.

The current study used data from more than $95 \%$ of the total population of high-level Portuguese swimmers belonging to three age groups. Results suggest that grip isometric strength and swimming performance have a variable relationship overall, being small or even negative for most short distances, but being quite large for several race performances, particularly the females' $100-\mathrm{m}$ freestyle. For talent identification in females, handgrip isometric strength could be an acceptable parameter used as a proxy for overall strength, and thus in general as a rough selection proxy for overall performance (Silva, et al., 2007). Certainly, other factors such as efficient technique and specific aerobic training seem far more important than general body strength, particularly in boys, as reflected in grip. Moreover, grip isometric strength does not seem specific enough to the requirements of competitive swimming (Morouço, et al., 2011). All the swimming strokes and races involve complex, coordinated, heavily aerobic muscle fiber contraction with 40 to 200 or more repetitions (Morouço, et al., 2011). Thus, swimming does not involve peak maximal impulsive power output (e.g., maximal single repetition).

Strength is related to the total number of muscle fibers, their area and tension, and to the percentage of fibers activated. Handgrip strength is a measure of the maximum isometric contraction due to the flexing action of all the finger joints with the maximum voluntary force the participant is able to exert under normal biokinetic conditions (Richards, Olson, \& Palmiter-Thomas, 1996; Bohannon, 1997). However, it is reported that an increase in handgrip isometric strength is closely related to the overall physical strength of an individual (Foo, 2007). The positive relationship 
that grip isometric strength has with other physiological parameters such as body mass, height, and muscle mass (Fabsitz, Sholinsky, \& Carmelli, 1994; Hewitt, 1997) may explain its scope as an overall indicator of muscle function. Moreover, its high heritability coefficient can be explained by the genetic stability of these correlated physiological traits (Carmelli, \& Reed, 2000).

The selection of handgrip for this study is also based on the fact that these correlated physiological traits are themselves related to swimming performance. Indeed, the swimmer's height (and presumably body mass) appears to be an important anthropometric parameter in shorter swimming events (Mazza, Ackland, Bach, \& Cosolito, 1993; Lees, 2002; Linder, Mohamed, De Lorenzo, \& Poppl, 2003; Silva, et al., 2007). In fact, in the current study, swimmer's height had a strong correlation with swimming performance, particularly with female's 100-m backstroke $(r=.83, p=.003$ for juvenile swimmers) and 100-m freestyle ( $r=.73, p=.005$ for junior swimmers; $r=.55, p=.03$ for senior swimmers) performance (these data are not shown). Neverthless, no statistically significant correlations were found for grip strength in both hands when expressed per kilogram of body weight.

The assumption for using handgrip isometric strength has never been quite clear, despite its being included in some batteries of swimmers evaluations in different studies (Carzola, 1993; Geladas, et al., 2005; Silva, et al., 2007; Zampagni, et al., 2008). For the most part, these studies showed this test had a significant relationship with swimming performance. Yet, the present study used a much larger sample to investigate the relationship over a broad age group of elite swimmers. The results show that the correlation of this parameter with performance seems to differ between the sexes. Females' grip isometric strength had moderate to high positive correlations with the performance at different strokes and distances across all age groups. However, this same correlation was not observed among boys and men.

The association between strength and performance becomes more evident at high swimming velocities, specifically in shorter duration events (Toussaint \& Vervoorn, 1990; Klentrou \& Montpetit, 1991; Roberts, Termin, Reilly, \& Pendergast, 1991; Hawley, Williams, Vickovic, \& Handcock, 1992; Geladas, et al., 2005). Neverthless, sprinting velocity is also closely dependent on coordination and technique (Cronin, Jones, \& Frost, 2007). Therefore, it makes sense that the influence that each of these factors has on swimming velocity will depend on its state of development. On this basis, swimmers who already have great muscle capacity would tend to improve their performance by optimizing their swimming technique rather than by additional increases in maximum strength (Costill, Sharp, \& Troup, 1980; Montpetit, 1981; Costill, King, Holdren, \& Hargreaves, 1983; Christensen \& Smith, 1987; Toussaint \& Vervoorn, 1990; Klentrou \& Mont- 
petit, 1991; Roberts, et al., 1991; Hawley, et al., 1992). From this perspective, differences in swimming technique may be the most crucial parameter of swimming performance. This could be the main reason why no significant correlations were found for isometric grip strength in male age group swimmers. Likewise, the consistently higher correlations found among females across all strokes and distances may be because these swimmers are relatively weaker in terms of body strength (assuming that grip strength is strongly correlated with overall physical strength). Indeed, isometric grip strength was statistically significantly lower among females in all age groups measured, even when adjusted for body weight. This hypothesis needs to be tested in further studies.

Research also indicates significant relationships between handgrip isometric strength and age (Kellor, Frost, Silberberg, Iversen, \& Cummings, 1971; Larsson, Grimby, \& Karlsson, 1979; Agnew, Dip, \& Man, 1982; Fike \& Rousseau, 1982; Mathiowetz, et al., 1985). Kellor, et al.'s (1971) data supported a linear inverse relationship, indicating that maximal hand strength is achieved at 20 years old and then decreases with increasing age. Other studies reported a curvilinear relationship, with hand strength peaking somewhere between 25 and 50 years of age and decreasing thereafter (Kellor, et al., 1971; Agnew, et al., 1982; Fike \& Rousseau, 1982; Mathiowetz, et al., 1985). However, these studies have not been conducted in swimmers or even in high-level athletes. Current results show (Table 2) a statistically non-significant decrease in the strength for both hands at around 14 years old for girls. As for boys, the data showed only slight increases in the strength for both hands across these age groups. Therefore, the linear inverse relationship between hand isometric strength and age up to 20 years old presented by Kellor's study (1971) may not apply to high-level athletes. Moreover, the increase of hand isometric strength with age and the time of relative peak strength seem to differ between sexes.

Some limitations should be noted. First, these results may not be applied to average swimmers at comparable ages. Second, the literature is contradictory and inconsistent regarding the effects of elbow position in the measurement of handgrip strength. The inconsistency of results may arise from the heterogeneity of the samples, their physical condition, and even some undiagnosed physical problems. Furthermore, the restrictions imposed on the assessments of these high-level swimmers did not allow the use of other complementary variables. In future studies it would be interesting to include other non-specific parameters that have been proposed as having high hereditary coefficients to reflect strength in other muscle groups (e.g., lower limbs) as well as the assessment of indicators of technical quality, coordination, and propulsive efficiency.

Conclusion

The results suggest that handgrip isometric strength seems to be re- 
lated to performance of some swimming events, namely to the 100-m freestyle and in female swimmers. For all other distances and strokes than female's 100-m freestyle, technique, and training are probably more influential. Hence, for talent identification in females, handgrip isometric strength could be an acceptable parameter used as a proxy for overall strength, and thus in general, as a rough selection proxy for overall swimming performance.

\section{REFERENCES}

Agnew, P. J., Dip, O. T., \& Man, F. (1982) Hand function related to age and sex. Archives of Physical Medicine and Rehabilitation, 63, 269-271.

BlANKSBY, B. B. (1980) Measures of talent identification in competitive swimming. Sports Coach, 4(4), 13-19.

BLoom, B. S. (1985) Developing talent in young people. New York: Ballentine.

Bloomfield, J. (1995) Talent identification and profiling. In J. Bloomfield, P. A. Fricker, \& K. D. Fitch (Eds.), Science and medicine in sport. Malden, MA: Blackwell Science Cambridge. Pp. 206-221.

BoHANNON, R. W. (1997) Reference values for extremity muscle strength obtained by hand-held dynamometer from adults aged 20 to 79 years. Archives of Physical Medicine and Rehabilitation, 78, 26-32.

Bомpa, T. O. (1985) TTalent identification. In Sports: Science Periodical on Research and Technology in Sport. Physical Testing G1. Ottawa, Canada: Coaching Association of Canada.

Carmelli, D., \& Reed, T. (2000) Stability and change in genetic and environmental influences on hand-grip strength in older male twins. Journal of Applied Physiology, 89, 1879-1883.

Carzola, G. (1993) Specific tests to the swimmer evaluation. Paris: Cestas Association pour la recherche et l'evaluation en activité physique et en sport, Editions Vigot.

Christensen, C., \& SMith, G. (1987) Relationship of maximum sprint speed and maximal stroking force in swimming. Journal of Swimming Research, 3(2), 18-20.

Cortis, C., Tessitore, A., Perroni, F., Lupo, C., Pesce, C., Ammendolia, A., \& Capranica, L. (2009) Interlimb coordination, strength, and power in soccer players across the lifespan. Journal of Strength and Conditioning Research, 23(9), 2458-2466.

Costill, D., King, D., Holdren, A., \& Hargreaves, M. (1983) Sprint speed vs. swimming power. Swimming Technique, 20-22.

Costill, D., Sharp, R., \& Troup, J. (1980) Muscle strength: contributions to sprint swimming. Swimming World, 21, 29-34.

Cronin, J., Jones, J., \& Frost, D. (2007) The relationship between dry-land power measures and tumble turn velocity in elite swimmers. Journal of Swimming Research, $17,17-23$.

Dopsaj, M., Matkovic, I., Thanopoulos, V., \& Oкicic T. (2003) Reliability and validity of basic kinematics and mechanical characteristics of pulling force in swimmers measured by the method of tethered swimming with maximum intensity of 60 seconds. Physical Education \& Sport, 1(10), 11-12.

FABSitz, R. R., Sholinsky, P., \& CARMELLI, D. (1994) Genetic influences on adult weight gain and maximum body mass index in male twins. American Journal of Epidemiology, 140, 711-720. 
Fernandes, R. J., Marinho, D. A., Barbosa, T. M., \& Vilas-Boas, J. P. (2006) Is time limit at the minimum swimming velocity of $\mathrm{VO}_{2}$ max influenced by stroking parameters? Perceptual and Motor Skills, 103, 67-75.

FIKE, M. L., \& RousSEAU, E., (1982) Measurement of adult hand strength: comparison of two instruments. Occupational Therapy Journal of Research, 2, 43-49.

Foo, L. H. (2007) Influence of body composition, muscle strength, diet, and physical activity on total body and forearm bone mass in Chinese adolescent girls. British Journal of Nutrition, 98(6), 1281-1287.

Frederiksen, H., Gaist, D., Christian Petersen, H., Hjelmborg, J., McGue, M., Vaupel, J. W., \& Christensen, K. (2002) Hand grip strength: a phenotype suitable for identifying genetic variants affecting mid- and late-life physical functioning. Genetic Epidemiology, 23, 110-122.

Frederiksen, H., Hjelmborg, J., Mortensen, J., McGue, M., Vaupel, J. W., \& Christensen, K. (2006) Age trajectories of grip strength: cross-sectional and longitudinal data among 8,342 Danes aged 46 to 102. Annals of Epidemiology, 16(7), 554-562.

Fry, A. C., Ciroslan, D., Fry, M. D., Leroux, C. D., Schilling, B. K., \& Chiu, L. Z. (2006) Anthropometric and performance variables discriminating elite american junior men weightlifters. Journal of Strength and Conditioning Research, 20(4), 861-866.

Garrido, N., Marinho, D., Reis, V., van den Tillaar, R., Costa, A., Silva, A., \& Marques, M. C. (2010) Does concurrent dry land strength and aerobic training inhibit strength and swimming performance in young competitive swimmers? Journal of Sports Science and Medicine, 9, 300-310.

Geladas, N. D., Nassis, G. P., \& Pavlicevic, S. (2005) Somatic and physical traits affecting sprint swimming performance in young swimmers. International Journal of Sports Medicine, 26(2), 139-144.

Girard, O., \& Millet, G. P., (2009) Physical determinants of tennis performance in competitive teenage players. Journal of Strength and Conditioning Research, 23(6), 1867-1872.

Haidar, S., Kumar, D., Bassi, R., \& Deshmukh, S. (2004) Average versus maximum grip strength: which is more consistent. Journal of Hand Surgery: British Volume, 29(1), 82-84.

Hansen, L., Bangsbo, J., Twisk, J., \& Klausen, K. (1999) Development of muscle strength in relation to training level and testosterone in young male soccer players. Journal of Applied Physiology, 87(3), 1141-1147.

Hawley, J. A., Williams, M. M., Vickovic, M. M., \& Handcock, P. J. (1992) Muscle power predicts freestyle swimming performance. British Journal of Sports Medicine, 26, 151-155.

HewitT, J. K. (1997) The genetics of obesity: what have genetic studies told us about the environment, Behavior Genetics, 27, 353-358.

Hughes, S., LyONS, B., \& MAYO, J. (2004) Effect of grip strength and grip strengthening exercises on instantaneous bat velocity of collegiate baseball players. Journal of Strength and Conditioning Research, 18(2), 298-301.

Kellor, M., Frost, J., Silberberg, N., Iversen L., \& Cummings, R. (1971) Hand strength and dexterity: norms for clinical use. American Journal of Occupational Therapy, 25(2), 77-83.

Keskinen, K., TilLI, L. J., \& Komi, P. (1989) Maximum velocity swimming: interrelationships of stroking characteristics, force production and anthropometric variables. Scandinavian Journal of Sports Sciences, 11(2), 87-92. 
KJendlie, P. L., Ingjer, F., Stallman, R., \& Stray-Gundersen, J. (2004) Factors affecting swimming economy in children and adults. European Journal of Applied Physiology, 93, 65-74.

KJendie, P. L., \& Thorsvald K. (2006) A tethered swimming power test is highly reliable. Portuguese Journal of Sport Sciences, 6(Supl. 2), 231-233.

Klentrou, P. P., \& Montpetit, R. R. (1991) Physiological and physical correlates of swimming performance. Journal of Swimming Research, 7(1), 13-18.

Larsson, L., Grimby, G., \& Karlsson, J. (1979) Muscle strength and speed of movement in relation to age and muscle morphology. Journal of Applied Physiology, 46, 451-456.

LEES, A. (2002) Technique analysis in sports: a critical review. Journal of Sports Science, 20, 813-828.

Linder, R., Mohamed, E. I., De Lorenzo, A., \& Poppl, S. J. (2003) The capabilities of artificial neural networks in body composition research. Acta Diabetol, 40(Suppl. 1), S9-S14.

Marinho, D. A., Barbosa, T. M., Reis, V. M., KJendlie, P. L., Alves, F. B., Vilas-Boas, J. P., Machado, L., Silva, A. J., \& RouboA, A. I. (2010) Swimming propulsion forces are enhanced by a small finger spread. Journal of Applied Biomechanics, 26, 87-92.

Mathiowetz, V., Kashman, N., Volland, G., Weber, K., Dowe, M., \& Rogers, S. (1985) Grip and pinch strength: normative data for adults. Archives of Physical Medicine and Rehabilitation, 66, 69-74.

Mazza, J., Ackland, T., Bach, T., \& Cosolito, P. (1993) Absolute body size. In L. Carter, \& T. Ackland (Eds.), Kinantropometry in aquatic sports: a study of world class athletes. Champaign, IL: Human Kinetics. Pp. 15-54.

Milliken, L. A., Faigenbaum, A. D., Loud, R. L., \& Westcott, W. (2008) Correlates of upper and lower body muscular strength in children. Journal of Strength and Conditioning Research, 22, 1339-1346.

MontPETIT, R. R. (1981) Maximal voluntary propelling force in swimming. Paper presented at the meeting of the American Swim Coaches Association, Chicago, IL, September.

Morouço, P., Keskinen, K. L., Vilas-Boas, J. P., \& Fernandes, R. J. (2011) Relationship between tethered forces and the four swimming techniques performance. Journal of Applied Biomechanics, 27(2), 161-169.

NigG, B. M. (1983) Selected methodology in biomechanics with respect to swimming. In A. P. Hollander, P. A. Huijing, \& G. De Groot (Eds.), Biomechanics and medicine in swimming. Champaign, IL: Human Kinetics, 72-80.

Olbrecht, J., Madsen, O., Mader, A., Liesen, H., \& Hollmann, W. (1985) Relationship between swimming velocity and lactic concentration during continuous and intermittent training exercises. International Journal of Sports Medicine 6(2), 74-77.

OXFORD, K. L. (2000) Elbow positioning for maximum grip performance. Journal of Hand Therapy, 13, 33-36.

Pearson, D. T., Naughton, G. A., \& Torode, M. (2006) Predictability of physiological testing and the role of maturation in talent identification for adolescent team sports. Journal of Science and Medicine in Sport, 9(4), 277-287.

Rantanen, T., Pertti, E., Kauppinen, M., \& HeikKInen, E. (1994) Maximal isometric muscle strength and socioeconomic status, health, and physical activity in 75-year-old persons. Journal of Aging and Physical Activity, 2, 206-220. 
Reilly, T., Williams, A., \& Richardson, D. (2008) Talent identification and development in football. In R. Fisher, \& R. Bailey (Eds.), Perspectives, the multidisciplinary series of physical education and sport science: talent identification and development, the search for sporting excellence. Berlin, Germany: International Council of Sport Science and Physical Education. Pp. 183-199.

Richards, L., Olson, B., \& PAlmiter-Thomas, P. (1996) How forearm position affects grip strength. American Journal of Occupational Therapy, 50, 133-139.

Roberts, A. J., Termin, B., Reilly, M. F., \& Pendergast, D. R. (1991) Effectiveness of biokinetic training on swimming performance in collegiate swimmers. Journal of Swimming Research, 7(3), 5-11.

Ross, W. D., \& Marfell-Jones, M. J. (1991) Kinanthropometry. In J. D. MacDougall, H. A. Wenger, \& H. J. Green (Eds.), Physiological testing of the high-performance athlete. Champaign, IL: Human Kinetics. Pp. 233-308.

Rотн, S. (2007) Genetics primer for exercise science and health. Champaign, IL: Human Kinetics.

Sharp, R., Troup, J., \& Costill, D. (1982) Relationship between power and sprint freestyle swimming. Medicine E Science in Sports E Exercise, 14, 53-56.

Silva, A. J., Costa, A. M., Oliveira, P. M., Reis, V. M., Saavedra, J., Perl, J., Rouboa, A., \& MARINHO, D. A. (2007) The use of neural network technology to model swimming performance. Journal of Sports Science and Medicine, 6, 117-125.

Stager, J. M., \& Coyle, M. A. (2005) Energy systems. In J. Stager \& D. Tanner (Eds.), Swimming: handbook of sports medicine and science. Malden, MA: Blackwell Science, $1-19$.

TAnaka, H., Costill, D. L., Thomas, R., Fink, W. J., \& Widrick, J. J. (1993) Dry-land resistance training for competitive swimming. Medicine \& Science in Sports \& Exercise, 25, 952-959.

TANAKA, H., \& SWENSEN, T. (1998) Impact of resistance training on endurance performance: a new form of cross-training? Sports Medicine, 28(6), 191-200.

Thomis, M. A., Beunen, G. P., Maes, H. H., Blimkie, C. J., Van, L. M., Claessens, A. L., Marchal, G., Willems, E., \& Vlietinck, R. F. (1998) Strength training: importance of genetic factors. Medicine \& Science in Sports \& Exercise, 30, 724-731.

Toussaint, H., \& Vervoorn, K. (1990) Effects of specific high resistance training in the water on competitive swimmers. International Journal of Sports Medicine, 11, 228-233.

VisnAPUU, M., \& JÜRIMÄE, T. (2007) Handgrip strength and hand dimensions in young handball and basketball players. Journal of Strength and Conditioning Research, 21(3), 923-929.

VisnAPUU, M., \& JÜRIMÄE, T. (2009) Relations of anthropometric parameters with scores on basic and specific motor tasks in young handball players. Perceptual and Motor Skills, 108, 670-676

WatAnABE, M., \& TAKAI, S. (2005) Age-related change of the factors affecting swimming performance in junior swimmers. Japanese Journal of Physical Fitness and Sports Medicine, 54, 353-361.

Zampagni, M. L., Casino, D., Benelli, P., Visani, A., Marcacci, M., \& De Vito, G., (2008) Anthropometric and strength variables to predict freestyle performance times in elite master swimmers. Journal of Strength Conditioning Research, 22(4), 1298-1307.

Accepted June 11, 2012. 